\title{
Correction: Distribution and determinants of pneumonia diagnosis using integrated management of childhood illness guidelines: a nationally representative study in Malawi
}

Uwemedimo OT, Lewis TP, Essien EA, et al. Distribution and determinants of pneumonia diagnosis using integrated management of childhood illness guidelines: a nationally representative study in Malawi. BMJ Glob Health 2018;3:e000506. doi: 10.1136/ bmjgh-2017-000506.

This article has been corrected since it first published. Owing to a communication lapse within the author team, the authors were not aware that findings from a related article that included co-author Humphreys Nsona were published while this article was under review and could be cited. This article focused on management of pneumonia cases once diagnosed. In addition, a typographic error resulted in the omission of an additional citation. The corrections are:

- Addition to Introduction, paragraph 4: 'Previous studies on assessment and management of pneumonia using nationally representative data have identified gaps in clinical assessment and poor prescribing practices. ${ }^{[29,30]^{\prime}}$

- Inclusion of missing citation, Discussion paragraph four at end of sentence, 'Prior analysis of the SPA data in Malawi found that nearly $30 \%$ of children who needed antibiotics did not receive them, while nearly $60 \%$ of children without antibiotic need were prescribed them.'

- Addition to Discussion, paragraph 4: 'Our results confirm low rates of appropriate assessment such as respiratory rate identified in an analysis of these data, with particularly weak performance among children over $1 .^{[30]^{\prime}}$

The references are:

[29] Johansson EW, et al. Integrated paediatric fever management and antibiotic over-treatment in Malawi health facilities: data mining a national facility census.' Malar J2016;15:396.

[30] Johannson EW, et al. Determinants of Integrated Management of Childhood Illness (IMCI) non-severe pneumonia classification and care in Malawi health facilities: Analysis of a national facility census. J Global Health 2017;7.

Open access This is an open access article distributed in accordance with the terms of the Creative Commons Attribution (CC BY 4.0) license, which permits others to distribute, remix, adapt and build upon this work, for commercial use, provided the original work is properly cited. See: http://creativecommons.org/licenses/by/4.0/

(C) Article author(s) (or their employer(s) unless otherwise stated in the text of the article) 2018. All rights reserved. No commercial use is permitted unless otherwise expressly granted.

BMJ Glob Health 2018;3:e000506corr1. doi:10.1136/bmjgh-2017-000506corr1

A) Check for updates 